Portland State University

PDXScholar

\title{
Distance Learning in Physics: an Investigation of Possible Benefits to Female Students in an Online Laboratory Environment
}

Caitlin Marie J. Kepple

Portland State University

Follow this and additional works at: https://pdxscholar.library.pdx.edu/honorstheses

Let us know how access to this document benefits you.

\section{Recommended Citation}

Kepple, Caitlin Marie J., "Distance Learning in Physics: an Investigation of Possible Benefits to Female Students in an Online Laboratory Environment" (2017). University Honors Theses. Paper 398.

https://doi.org/10.15760/honors.394

This Thesis is brought to you for free and open access. It has been accepted for inclusion in University Honors Theses by an authorized administrator of PDXScholar. Please contact us if we can make this document more accessible: pdxscholar@pdx.edu. 


\title{
Distance Learning in Physics: An Investigation of Possible Benefits to Female Students in an Online Laboratory Environment
}

\author{
by \\ Caitlin Kepple \\ An undergraduate honors thesis submitted in partial fulfillment of the \\ requirements for the degree of
Bachelor of Science
in
University Honors
and
Physics \\ Thesis Advisor \\ Dr. Erik Bodegom
}

Portland State University 


\begin{abstract}
As the online class format becomes more popular, many see this as an opportunity to study how those who are typically underrepresented in the classroom may benefit from an online setting. In particular, the field of physics is well known for having a major gender disparity even at the undergraduate level. Recent literature suggests that female students may actually prefer online classes in physics, although studies have not found online classes to demonstrate any particular performance increase when comparing to those who take the class on-campus. This study uses data from introductory physics laboratories at Portland State University during the Fall 2016 term to investigate possible differences in student attitudes and performance levels in both class formats. After comparing students' pre and post test scores, survey data and final lecture class scores, the online students tended to score higher and say they would prefer to take another online lab if given the chance. However, this was the case for all students (male and female included) which means students' scores and/or class grades may have been affected by the lab format/equipment itself rather than solely student preference.
\end{abstract}


Table of Contents

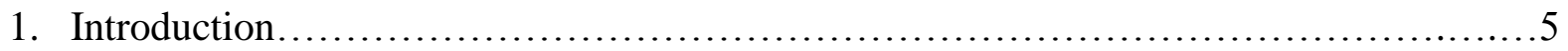

a. Gender Disparity in Physics...........................................

b. IOLab Device..........................................................

2. Literature Review..........................................................

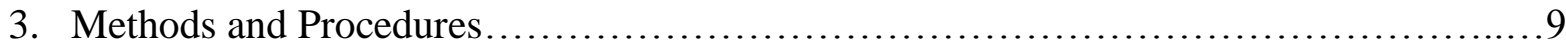

a. Student Population.................................................9

b. Qualitative Assessment: Student Interviews and Surveys....................10

c. Quantitative Assessment: Force and Motion Concept Evaluation................11

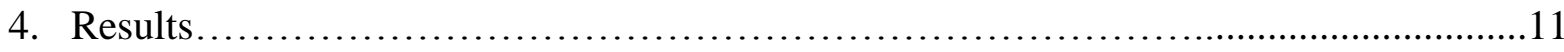

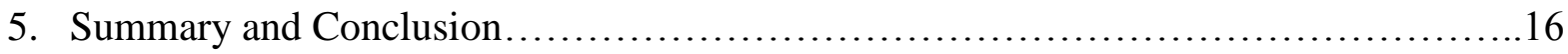

a. Literature and Data Comparison...................................... 16

b. Limitations and Strengths............................................... 17

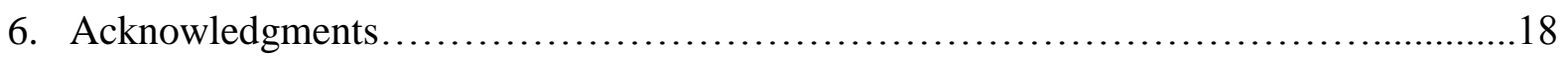

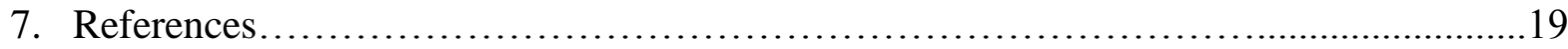

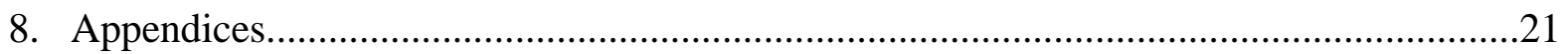




\section{Figures}

Figure 1 - IOLab Device used for the study, enables students to easily complete labs at home.....7

Figure 2 - Interview Questions for Online Students............................................. 10

Figure 3 - Graph showing pre and post scores with all 3 types of classes....................................13

Figure 4 - Graph showing pre and post scores for female students............................................14

Figure 5 - Graph showing pre and post scores for male students..............................................15 


\section{Tables}

Table 1 - Table of all FMCE scores, Average gain, and Lecture Grades (All Students).............13

Table 2 - Table of all FMCE scores, Average gain, and Lecture Grades for female students......14

Table 3 - Table of all FMCE scores, Average gain, and Lecture Grades for male students.........15 


\section{Introduction}

It is well known that females are generally underrepresented in the field of physics, and this trend is no different in the physics classroom. In recent years, many physics departments have begun experimenting with the transition to a completely online classroom with the hope to make the experience more convenient for students and instructors [1]. Data from a recent study by Cavallo, Rozmann and Potter [2] shows that female students may actually prefer online communication with their physics instructors and peers over face-to-face. A joint project through PSU and Chemeketa Community College has shown that this preference may possibly be extended to the laboratory. A new device, known as the IOLab, has enabled a few physics laboratories to function completely online, where the students complete each lab at home and then submit their work online to the instructor. From the classes offered so far, females not only have increased representation, but also in some cases make up the majority of these online labs. One question that arises from this observation is what caused this spike in enrollment? Is there some underlying motivation for female students to choose an online format over a face-to-face one, and could this preference be used to reduce the gender gap within physics? My thesis will attempt to determine a few possible answers to this question by administering surveys to current online lab students, as well as reviewing current research on the subject.

\section{Gender Disparity in Physics}

As online classes become more popular in the university setting, the need for understanding the student population is vital to its success. While women who work in the field of physics itself represent less than $20 \%$ of the population [3], students who must take the introductory sequence of physics have a much more favorable ratio, though still much less than the optimal $50 \%$. It has been shown in multiple studies [4] that female students tend to prefer an online class/lab 
environment rather than the traditional in-class setting. In particular, the average female representation in an introductory physics lab is less than half, while online labs regularly have the majority of students as female [5]. While it hasn't been shown directly that women benefit from this change any more than men might, there is a clear preference [6]. The question that remains is what characteristics affect student's success in online labs and how can this be used to reduce the prevalent gender disparity within physics?

During the Fall 2016 term at PSU, the physics department set up a trial online lab using IOLab technology and two on-campus labs using the same device. The rest of the labs were set up in the traditional format. Our group then collected data for each of these types of labs so that the possible benefits for each individual student may be measured.

\section{IOLab Device}

The IOLab technology that was used for the main lab sections of this project enable the students to do seven out of eight of the labs using this one device. To give a brief image of how it performs, the IOLab includes a force sensor, an accelerometer, and the ability to measure position, velocity and acceleration. These, along with other sensors included in the device, enable the student to complete the lab anywhere they have access to a computer.

The IOLab is essentially a compact microcontroller (see Fig. 1) that includes a number of sensors that sends measurements in real time to software installed on a computer. Traditionally, physics labs utilize a number of different devices to complete the course, which can be extremely expensive when attempting to make the course available to students doing the labs at home. With the IOLab, students are able to complete these same labs using only one device. Ideally, these will someday be the standard for any online physics lab that students are able to complete at home and for a fair price. With the call for more and more online class environments, this is a 
growing need within the field of physics and will likely continue to gain popularity in the coming years.

Figure 1 - IOLab Device used for the study, enables students to easily complete labs at home

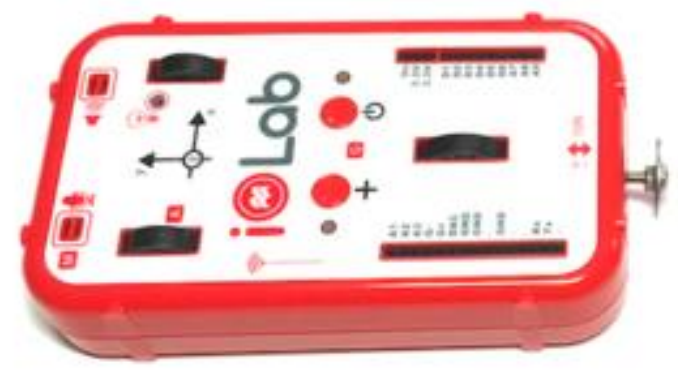

\section{Literature Review}

Because online labs are still relatively unusual in the university system, there are not many studies that overlap perfectly the question at hand. Instead, five related projects that either include distance learning in physics or studies on gender disparities in physics were looked at. The article that was most closely related to the topic was one by Dr. Peter Gustafsson [7]. The article Gender inclusive physics education--a distance case is a continuation of a project by Dr. Gustafsson and his colleagues that was published in 2002 [8]. Gustafsson concludes that an online learning environment is advantageous for both genders. He also notes that no difference in performance was seen between the two genders when measuring throughput (productivity). One other part of the study was to include cooperative work for the students. The conclusion from this was that both genders regard Internet courses differently. While female students tend to see it as a means to develop communication and collaborative work, male students use it more as a 
competitive tool to either elevate their own status or lower that of others. Nonetheless, these key differences between how women and men perceive online learning show that there are a number of social-psychological factors that influence how both types of students learn and whether "fitting in" will affect their success in a course. These factors are discussed further in a study by Lewis, et. al. which concludes that these can ultimately define whether a female student will stay in physics or not [9].

The second article is one by Dr. Jillian Lang [10]. Her study focused on remote physics labs, but did not have a gender component. In the article, Lang recognizes that online labs may have quite a few advantages for marginalized students, students in remote communities, and disabled students. After comparing the grades of six face-to-face students and six online students, Lang concluded that there were no significant differences in the work of either type of student. The final three articles of this review all did a comparative study between genders in an introductory physics course attempting to identify some of the key areas that female students may begin to fall behind and whether a reformed course may reduce this gap. The article by Cavallo, Potter and Rozman investigated possible differences in learning and motivation constructs among male and female students and found that male students had significantly higher self-efficacy, performance goals, and physics understanding than female students. The authors attest that these findings show that different variables in females' learning and motivation may be important to take into consideration when teaching an introductory physics course. A study by Dr. Teresa Larkin had similar findings. According to her analysis, Force Concept Inventory (FCI) gains are significantly lower for female students as compared to males [11]. This conclusion was the same Dr. Docktor and Dr. Heller's study looking at both FCI gains and course grades for a number of different studies all from introductory physics classes [12]. Their 
study however, found that while there was a large gap in FCI scores for pre and post-instruction, there was no major difference in course grades between men and women. This raises the question of whether it is the method in which students are measured is somehow biased toward males.

\section{Methods and Procedures}

The data taken for this research had both a qualitative component, along with a quantitative one. A select population of students from the lab courses were given an interview and an attitudinal survey at the end of the ten-week course. These same students were also given the Force and Motion Conceptual Inventory (FMCE) exam at the beginning and end of the term. Together, these tools would hopefully offer an overall look at the attitudinal differences between male and female students, along with possible achievement differences in the two different lab settings.

\section{Student Population}

The population of students for this study included one section (on average about 25 students) who completed the lab online and two sections of students who also used the IOLab technology, but instead took the lab in-person. Three control sections were also included who did not use IOLab at all during the labs and took the class on-campus. Unfortunately, not all of the students were offered the interview or the survey sections of the analysis and the students taking the traditional in-class lab were only given a shortened version of the FMCE test rather than the fulllength one. Both of these factors may have affected the overall gains measured for these students, and will hopefully be improved in the future.

\section{Qualitative Assessment: Student Interviews and Surveys}

Because the online class was the main focus of the study, each student was given a short 
interview after completing the course. The questions for the interview are shown in Figure 2

below.

Figure 2 - Interview Questions for Online Students

\begin{tabular}{|l|}
\hline$\circ \quad \begin{array}{l}\text { Aside from convenience, no } \\
\text { commute time, etc., why did you } \\
\text { take this class online rather } \\
\text { than on-campus? }\end{array}$ \\
What did you like about the \\
IOLab setup? \\
What do you think needs \\
improved? \\
What would you recommend as \\
general advice for future \\
students who are thinking \\
about taking an online physics \\
lab?
\end{tabular}

The purpose of the interview was to gain more insight on what motivated each student to take the online lab, and whether they found it reasonable to complete or not. Because this class was predominantly female, these questions would also serve to gain insight on whether female students as a whole saw the distance course as a better option for any particular reason. Both the online students and those who completed the labs using the IOLab were also given an attitudinal survey at the end of the term (See Appendix A and B). This survey was mostly to give students a chance to give direct feedback on any difficulties they saw in using the IOLab or with the format of the class itself. Students were also asked how long they spent completing each lab and homework. This could then be compared against the standard three hours it took the in-class students to finish their work. The other question of interest was asking the online students whether they would be interested in taking another online physics lab and asking the in-class 
students whether they felt like they would be willing to take an online lab. Together, the responses from the online class could be compared with those of the face-to-face class. To add to this, a qualitative component of analysis was also done for this project.

\section{Quantitative Assessment: Force and Motion Conceptual Evaluation}

All students included in the study took a standardized test that is commonly used within physics education community known as the Force and Motion Conceptual Evaluation (FMCE) both before and after completing the course. This technique is commonly used to roughly measure how much a student has learned throughout the course, otherwise known as "gain". Equation (1) below shows how learning gain is measured in education research.

$$
<\mathrm{g}>=\frac{\text { postscore } \%-\text { prescore } \%}{100}-\text { prescore } \%
$$

In the section on Literature Review, most studies used a similar evaluation called the Force Concept Inventory (FCI) and is regularly considered as adequately related to FMCE. Because the IOLab format is only offered during Fall term, the primary data for this study is limited to only one set of students and should be taken into account when drawing the final conclusions about the findings of this research.

\section{Results}

There were 19 students from the online class that were also able to complete the interview. For most of the interview questions, students' answers had very little overlap with each other. The question that directly asked students why they chose an online environment had 13 responses commenting on the convenience and/or "no time commitment" aspect. Four students also said they enjoy the independent learning style. There were essentially no differences in responses according to gender. The rest of the three questions on the interview had almost every response 
in regards to logistical details of the course and were not significant in adding to the final analysis of the interviews.

As for the surveys, there was a noticeable difference in the average time the online students reported spending on labs as compared those in-class. Students who took the online course reported on average taking over three hours to complete each lab and an average of one hour to complete each homework, while almost every student in the on-campus lab was able to complete both the lab and the homework in the allotted 3-hour lab period. This suggests over an hour difference in how much time the online students spent each week completing lab work.

Students were also asked in the survey whether they would take another online lab in the future (in-class students were asked whether they'd consider doing the lab online instead). Approximately $79 \%$ of online students responded to this question positively, saying that they would take another lab online if given the opportunity. On the flip side, over $60 \%$ of in-class students said they would not be willing to take an online lab. There is a chance that because there were some issues with the IOLab technology, students were more likely to have said no to this question knowing they would have had to deal with those issues on their own.

Students from all three class types were compared for the FMCE pre and post-instruction scores. Table 1 below shows the comparison without separating out for gender. The first column corresponds to students' average scores on the first day of class. Post FMCE is their average score after completing the course. Gain corresponds to how much the class average improved as a whole. The final column is the average lecture grade on a 4.0 scale. It was decided that because each lab is taught by a different person, it would be more consistent of a measure to use the lecture grade instead of the lab grade. The table is then followed by a graph in Figure 3 corresponding to pre and post FMCE scores. In both the case of gain and final lecture grade, the 
online IOLab students received noticeably higher scores than either of the two other types of classes. Although the average for online students started out lower than the IOLab in-class, their average gain was almost twice as much. Overall, both IOLab courses had at least twice the amount of gain that the traditional lab course had. The standard deviation was only calculated for the case of all students, since the sample size became too small when separating the data out by gender.

Table 1 - Table of all FMCE scores, Average gain, and Lecture Grade

\begin{tabular}{|c|c|c|c|c|}
\hline & Pre FMCE & Post FMCE & Gain & Lecture Grades \\
\hline Traditional $(\mathbf{n}=\mathbf{3 0})$ & $4.5(2.0 \%)$ & $7.7(5.0 \%)$ & $15.7 \pm 22.8$ & 2.69 \\
\hline IOLab In-Class $(\mathbf{n}=\mathbf{3 4})$ & $8.0(6.2 \%)$ & $12.4(8.2 \%)$ & $34.8 \pm 40.1$ & 2.64 \\
\hline IOLab Online $(\mathbf{n}=\mathbf{1 7})$ & $5.5(4.4 \%)$ & $17.0(7.0 \%)$ & $61.3 \pm 33.5$ & 2.81 \\
\hline
\end{tabular}

Figure 3 - Graph showing pre and post scores with all 3 types of classes

\section{Average Gain For All Students}

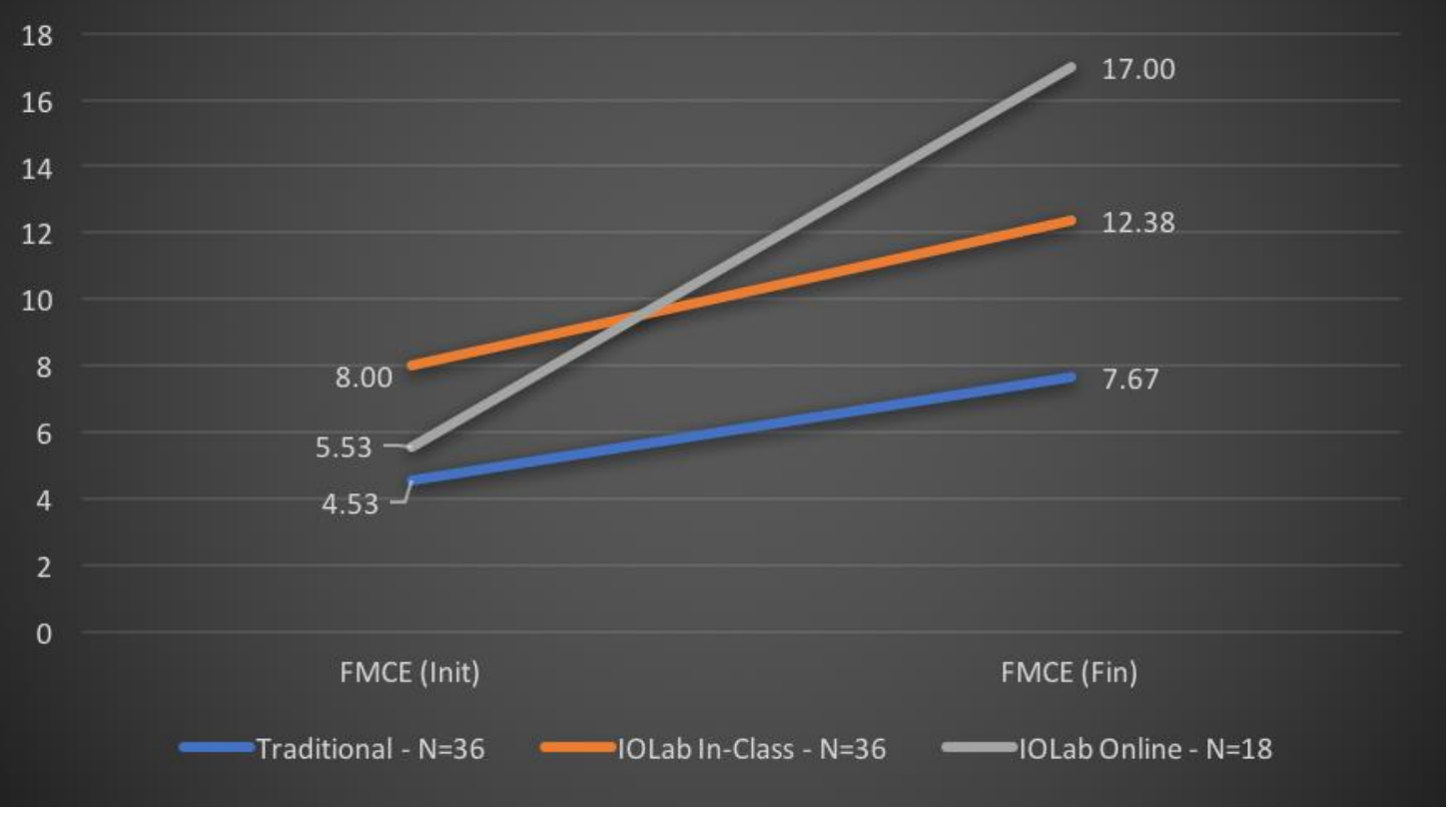


The data for the total class was then split up by gender. Table 2 and Figure 4 show the same categories for female students in each class. One will quickly notice that the students in the IOLab course had an initial score similar to those of the two on-campus classes. However, by the end of the course, the online students had jumped to having almost twice the average score of either on-campus class. This is contrasted in the average class grade for online students, as all three types of labs received about the same grade in lecture. As mentioned above, the data for female and male students individually does not have a standard deviation attached, because the sample size for each class became too small for it to be useful.

Table 2 - Table of all FMCE scores, Average gain, and Lecture Grades for female students

\begin{tabular}{|c|c|c|c|c|}
\hline & Pre FMCE & Post FMCE & Gain & Lecture Grades \\
\hline Traditional $(\mathbf{n}=\mathbf{1 6})$ & 4.3 & 6.5 & 10.3 & 2.81 \\
\hline IOLab In-Class $\mathbf{n}=\mathbf{1 7})$ & 5.0 & 7.2 & 10.0 & 2.57 \\
\hline IOLab Online $(\mathbf{n}=\mathbf{9})$ & 4.2 & 14.1 & 47.4 & 2.78 \\
\hline
\end{tabular}


Figure 4 - Graph showing pre and post scores for female students

\section{Average Gain For Female Students}

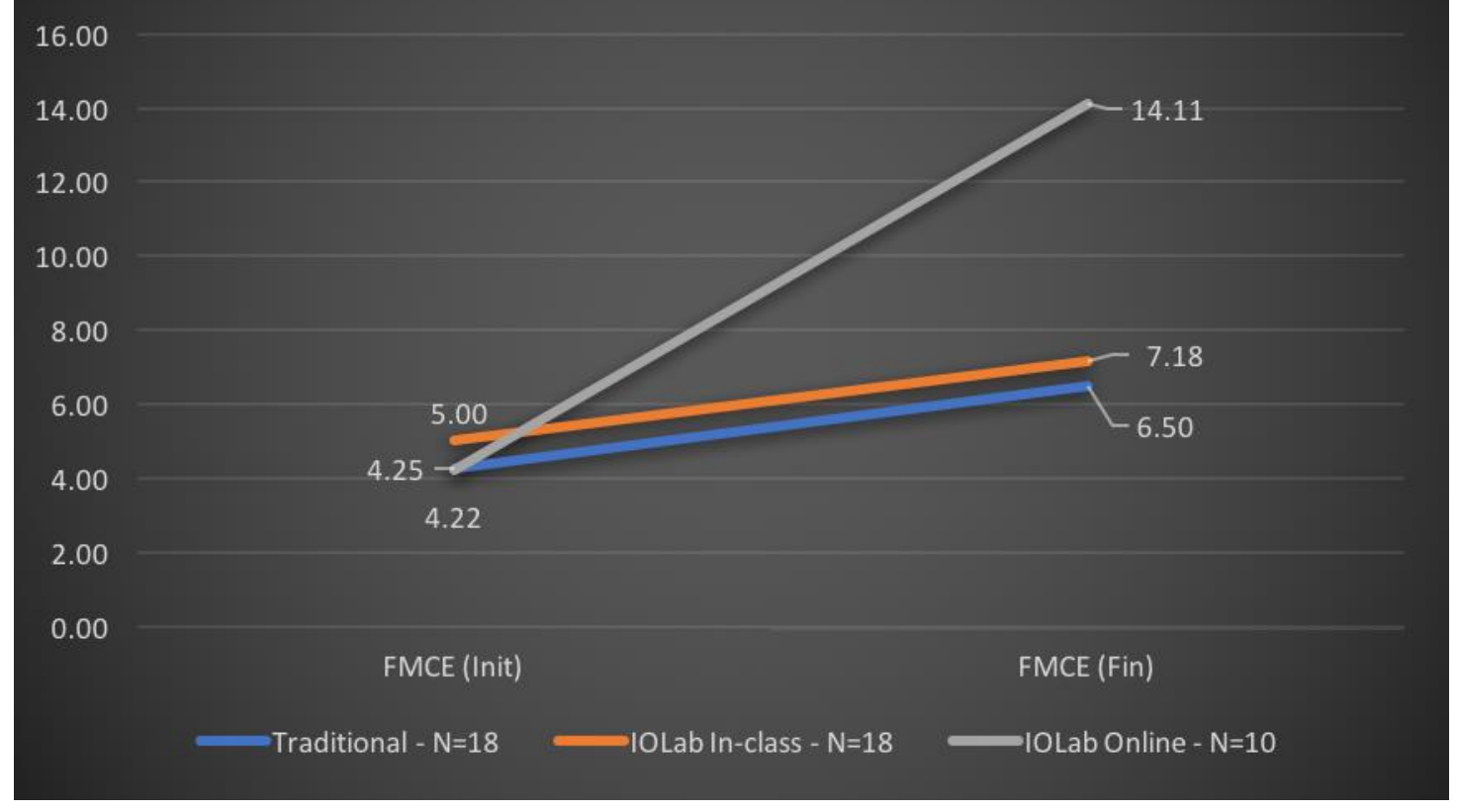

Table 3 and Figure 5 represent the data for male students in all three types of courses. By

studying the graph in this case, one will notice that for men there was not quite such a jump for online IOLab students as there was for women. However, the average GPA for online students was higher than both of the on-campus courses.

Table 3 - Table of all FMCE scores, Average gain, and Lecture Grades for male students

\begin{tabular}{|c|c|c|c|c|}
\hline & Pre FMCE & Post FMCE & Gain & Lecture Grades \\
\hline Traditional (n= 14) & 4.9 & 9.0 & 21.8 & 2.54 \\
\hline IOLab In-Class ( $=17)$ & 11.0 & 17.6 & 59.6 & 2.72 \\
\hline IOLab Online (n= 8) & 7.00 & 20.3 & 77.0 & 2.84 \\
\hline
\end{tabular}


Figure 5 - Graph showing pre and post scores for male students

\section{Average Gain For Male Students}

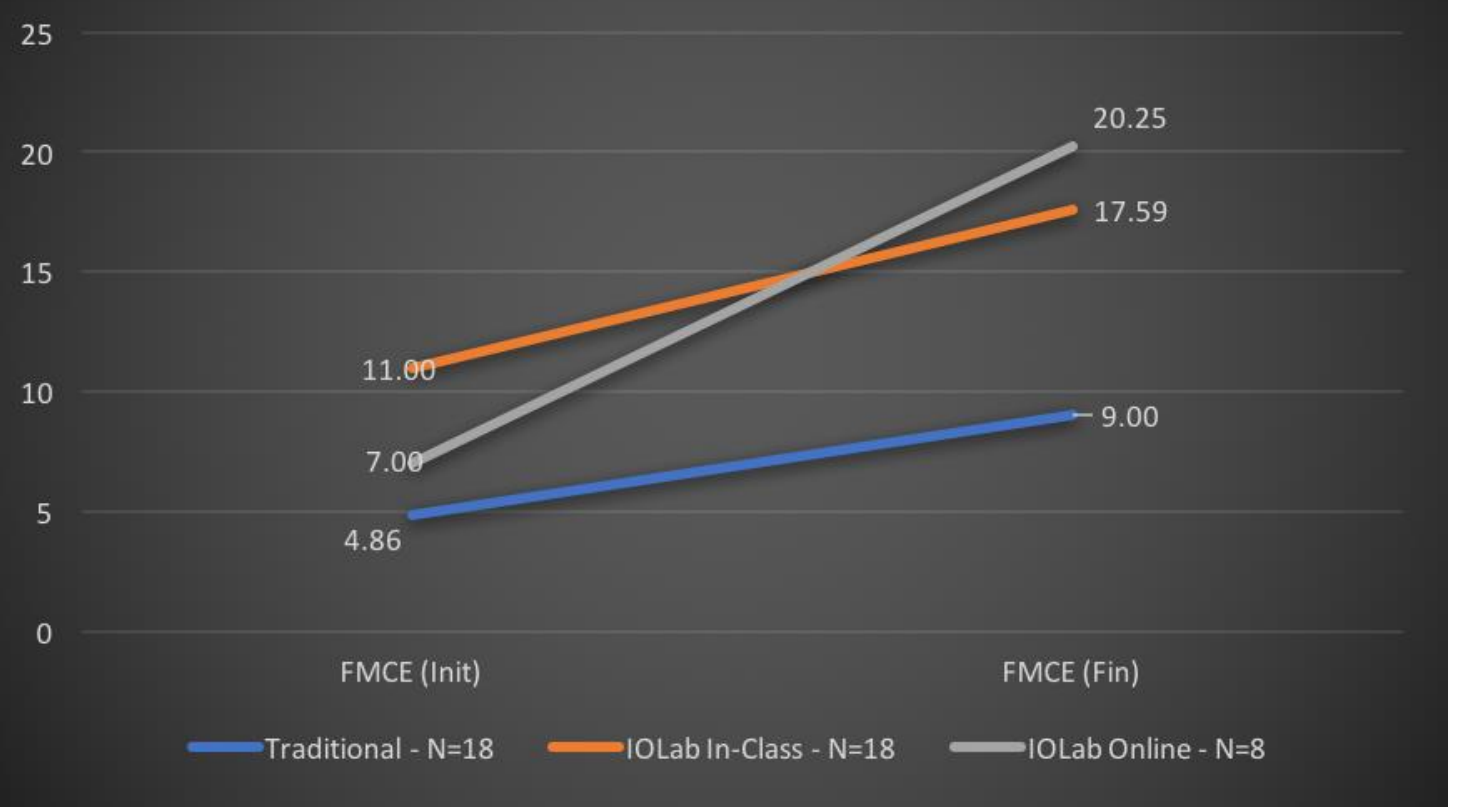

\section{Summary and Conclusion}

\section{Literature and Data Comparison}

The purpose of this study was to predict and understand how an online physics laboratory may benefit female students. Supporting literature stated that women regularly score lower on standardized tests in physics such as FCI or FMCE. There is also evidence that the qualities being tested for in students' success may have some bias toward male students' learning tendencies, making it inherently impossible for the women to score higher. By providing the opportunity to learn more independently and without the pressure of a face-to-face lab environment, female students may have some benefit to taking physics labs online. The results show that both female and male students scored better on the FMCE evaluation after taking the 
course online. The difference between females who took the class on campus versus online showed that online students scored almost twice as high. Women from all three types of labs had about the same course grade in the end. The vast majority of online students also said they would take another online lab if given the chance.

\section{Limitations and Strengths}

This research unfortunately had a number of limitations, as research in physics education often does. The online course is currently only offered once per school-year and therefore had an extremely small sample size. One other consideration that was not taken into account is the fact that both calculus-based and algebra-based students take the same lab. There may be some correlation between FMCE scores and/or lecture grades depending on whether the student was in the calculus or algebra-based class. In this case, a more in-depth form of analysis would be preferred. Perhaps the aspect that had the largest effect on the results is the difficulty most students had using the IOLab. As mentioned previously, this contributed to online students taking much longer to complete each lab and may have deterred some in-class students from thinking about the possibility of taking an online lab. If they had trouble with the device in class, this would almost definitely discourage them from trying to use it at home.

On the other hand, this project included many aspects of a physics course that could be more gender inclusive. By offering flexibility, convenience, and none of the pressure that a regular oncampus lab might have, any student could use this as a tool to become more comfortable with physics. Although an online course is not ideal for everyone, it might be one step closer to help reduce the gender gap in physics. 


\section{Acknowledgments}

Many thanks to my thesis advisor, Dr. Bodegom, for providing me with the opportunity to work with him on this project, as well as for offering numerous amounts of advice for this thesis. Thanks to the PSU physics department office manager, Kim, for helping organize and sort through data used for this research. 


\section{References}

[1] Brewe, E., Sawtelle, V., 2016, Editorial: Focused Collection: Gender in Physics, Physical Review Physics Education Research, v. 12, p. 020001.

[2] Cavallo, A., Rozman, M, Potter, W., 2004, Gender Differences in Learning Constructs, Shifts in Learning Constructs, and Their Relationship to Course Achievement in a Structured Inquiry, Yearlong College Physics Course for Life Science Majors, School Science and Mathematics, v. 104, n. 6, p. 288-300.

[3] Day, Stang, et. al., 2016, Gender gaps and gendered action in a first-year physics laboratory, Physical Review Physics Education Research, v. 12, n. 2, p. 020104.

[4] Anderson, D., Haddad, C., 2005, Gender, voice, and learning in online course environments, Journal of Asynchronous Learning Networks, v. 9, n. 1, p. 3-14.

[5] Caspi, A., et al., 2006, Participation in class and in online discussions: Gender differences, Computers \& Education, v. 50, p. 718-724.

[6] Eom, S., Wen, J., Ashill., 2006, The Determinants of Students' Percieved Learning Outcomes and Satisfaction in University Online Education: An Empirical Investigation*, Decision Sciences Journal of Innovation Education, v. 4, n. 2, p. 215-235

[7] Gustafsson, P., 2005, Gender inclusive physics education - a distance case, European Journal of Physics, v. 26, p. 843-849.

[8] Gustafsson, P., 2002, Physics teaching at a distance, European Journal of Physics, v. 23, p, 469-474.

[9] Lewis, K., et al., 2016, Fitting in or opting out: A review of key social-psychological factors influencing a sense of belonging for women in physics, Physical Review Physics Education Research, v. 12, p. 020110-1-020110-10. 
[10] Lang, J., 2012, Comparative Study of Hands-on and Remote Physics Labs for First Year University Level Physics Students, Transformative Dialogues: Teaching \& Learning Journal, v. 6, n. 1 .

[11] Larkin, T., 2011, A gender analysis of student learning in physics, Frontiers in Education Conference (FIE), p. F4H-1-F4H-7.

[12] Docktor, J., Heller, K., Gender Differences in Both Force Concept Inventory and Introductory Physics Performance, 2008, AIP Conference Proceedings, 1064:1, p. 15-18. 


\section{Appendix A}

\section{Survey for In-Class IOLab Students}

If you are willing to be contacted for more detailed feedback, please enter your name:

Please answer the following questions regarding the software, equipment, and lab instructions:

1. The IOLab software was easy to use

Strongly Agree $\quad$ Agree Neutral Disagree Strongly Disagree

2. The IOLab device was easy to use

$\begin{array}{llll}\text { Strongly Agree } & \text { Agree } & \text { Neutral } & \text { Disagree }\end{array}$

3. I enjoyed using the IOLab device

Strongly Agree Agree Neutral Disagree Strongly Disagree

4. I enjoyed using the IOLab software

Strongly Agree Agree Neutral Disagree Strongly Disagree

5. Compare your perception of learning using this style of lab instructions to the lab instructions you have used in other labs:

Learned much more with this style of lab instructions

Learned a bit more with this style of lab instructions

Learned about the same with this style of lab instructions

Learned a bit less with this style of lab instructions

Learned a lot less with this style of lab instructions and software

6. These labs helped me with my conceptual understanding of physics:

$\begin{array}{llll}\text { Strongly Agree } & \text { Agree } & \text { Neutral } & \text { Disagree }\end{array}$

7. I liked using the IOLab as a tool for learning physics:

$\begin{array}{llll}\text { Strongly Agree } & \text { Agree } & \text { Neutral } & \text { Disagree }\end{array}$

8. The homework for each lab was useful in cementing my understanding:
Strongly Agree
Agree
Neutral
Disagree
Strongly Disagree

9. I have gained a greater insight into the nature of the physical world:
Strongly Agree
Agree
Neutral
Disagree
Strongly Disagree

10. I have learned useful concepts from the laboratory course:
Strongly Agree
Agree
Neutral
Disagree
Strongly Disagree

11. The laboratory course added to my understanding of the lectures:
Strongly Agree
Agree
Neutral
Disagree
Strongly Disagree 
12. Knowing there are tens of very short YouTube videos online, explaining some of the more confusing parts of using IOLab and software, I could have done these labs at home:

Strongly Agree Agree Neutral Disagree Strongly Disagree

13. I would have rather done these labs at home than having to come to PSU:

Strongly Agree Agree Neutral Disagree Strongly Disagree

14. If you have any knowledge about the regular (the non-IOLab version) physics labs this term, in your opinion, the IOLab version is more useful in learning physics than the regular lab:

I don't know Agree Neutral Disagree

15. Did you spend time outside the classroom using IOLab software? If yes, how much time per homework/lab assignment would you say you spent using it?

16. What did you like most about the IOLab experience?

17. What did you like least about the IOLab experience?

18. What improvements would you like to see? 


\section{Appendix B}

\section{Survey for Online IOLab Students}

PH214 Survey - Fall 2016 Online

1. What is your major, if declared?

2. Have you taken other college classes with online labs? If so, then please compare the labs in PH 214 to those.

3. Which computer and operating system did you use?

4. Did you have any trouble installing the software or beginning the labs? Please be as specific as possible.

5. Did you have any trouble doing the labs (in terms of software or hardware, not understanding the physics)? Again, please be as specific as possible.

6. How much time did it take you on average to complete a lab? 
7. How much time did it take you on average to complete a homework?

8. Will you be taking any more physics labs? If yes, would you take another online lab given the chance?

9. Would you have chosen to do the online lab, knowing what you know now? 